This document is the accepted manuscript version of the following article:

Tsai, D. H., Riediker, M., Berchet, A., Paccaud, F., Waeber, G., Vollenweider, P., \& Bochud, M. (2019). Effects of short- and long-term exposures to particulate matter on inflammatory marker levels in the general population. Environmental Science and

Pollution Research, 26(19), 19697-19704. https://doi.org/10.1007/s11356-019-05194-y

\title{
Effects of short- and long-term exposure to particulate matter on inflammatory marker levels in the general population
}

Dai-Hua Tsai ${ }^{1,2}$, Michael Riediker ${ }^{3,4}$, Antoine Berchet ${ }^{5,6}$, Fred Paccaud ${ }^{2}$, Gerard Waeber ${ }^{7}$, Peter Vollenweider ${ }^{7}$, Murielle Bochud ${ }^{2 \S}$

${ }^{1}$ Department of Child and Adolescent Psychiatry and Psychotherapy, University Hospital of Psychiatry Zurich, University of Zurich, Zurich, Switzerland

2 Institute of Social and Preventive Medicine (IUMSP), Lausanne University Hospital (CHUV), Lausanne, Switzerland

3 Swiss Centre for Occupational and Environmental Health (SCOEH), Winterthur, Switzerland

${ }^{4}$ Institute for Work and Health (IST), University of Lausanne, Epalinges, Switzerland

${ }^{5}$ Laboratoire des Sciences du Climat et de l'Environnement (LSCE), CEA-CNRS-UVSQ, UMR8212, Gif-sur-Yvette 91191, France

${ }^{6}$ Swiss Federal Laboratories for Materials Science and Technology (EMPA), Dübendorf, Switzerland

${ }^{7}$ Department of Medicine, Internal Medicine, CHUV, Lausanne, Switzerland

§Corresponding author. Institute of Social and Preventive Medicine (IUMSP), Biopôle 2, Route de la Corniche 10, CH-1010 Lausanne, Switzerland. Telephone: +41 21314 0899; Fax: +41 21314 7373; E-mail address: murielle.bochud@chuv.ch 


\section{Abstract}

Background: The effect of particulate matter (PM) on health increase with exposure duration but the change from short to longer term is not well studied.

Objectives: We examined exposure to $\mathrm{PM}$ smaller $10 \mu \mathrm{m}\left(\mathrm{PM}_{10}\right)$ from short to longer duration and their associations with levels of inflammatory markers in the populationbased CoLaus cohort in Lausanne, Switzerland.

Methods: Baseline and follow-up CoLaus data were used to study the associations between $\mathrm{PM}_{10}$ exposure and inflammatory markers, including the high-sensitivity $\mathrm{C}$ reactive protein (CRP), as well as interleukin 1-beta (IL-1 $\beta$ ), interleukin 6 (IL-6), and tumornecrosis-factor alpha (TNF- $\alpha$ ) using mixed models. Exposure was determined for each participant's home address from hourly air-quality simulations at 5-meter resolution. Shortterm exposure intervals were one day, one week, and one month prior to the hospital visit (blood withdrawal); long-term exposure intervals were three and six months prior to the visit.

Results: In most time-windows, IL-6, IL-1 $\beta$ and TNF- $\alpha$ were positively associated with $\mathrm{PM}_{10}$. No significant associations were identified for CRP. Adjusted associations with longterm exposures were stronger and more significant than those for short-term exposures. In stratified models, gender, age, smoking status and hypertension only led to small modifications in effect estimates, though a few of the estimates for IL-6 and TNF- $\alpha$ became non-significant.

Conclusion: In this general adult cohort exposed to relatively low average $\mathrm{PM}_{10}$ levels, clear associations with markers of systemic inflammation were observed. Longer duration 
of elevated exposure was associated with an exacerbated inflammatory response. This may partially explain the elevated disease risk observed with chronic $\mathrm{PM}_{10}$ exposure. It also suggests that reducing prolonged episodes of high PM exposure may be a strategy to reduce inflammatory risk.

Keywords: Particulate matter, Inflammation, Short-term, Long-term, modeling, air pollution 


\section{Introduction}

Air pollution is a widely-acknowledged environmental risk factor globally, estimated to cause 3.3 million premature deaths per year worldwide (Lelieveld et al., 2015). Several studies have shown that exposure to particulate matter (PM) is associated with adverse cardiovascular effects (Brook et al. 2010). Moreover, PM-induced inflammation has been postulated to be one of the mechanisms behind cardiovascular disease (Brook et al., 2010, Pope and Dockery, 2006). Inflammatory markers are known to be associated with increased risk of developing cardiovascular disease (Kaptoge et al. 2014 ; Kofler et al. 2005). Levels of inflammatory markers can also be mediated by lifestyle factors, such as smoking, or physical activity (Bermudez et al. 2002; Colbert et al. 2004).

A series of epidemiologic studies have documented associations between short-term exposure to PM and inflammatory markers (Hassanvand et al. 2017; Hertel et al. 2010; Steinvil et al. 2008; Tsai et al. 2012), while long-term exposure also appears to play an important role. In one study in the United Kingdom (UK), an association was detected between long-term exposure to PM having aerodynamic diameter of $10 \mu \mathrm{m}$ or smaller $\left(\mathrm{PM}_{10}\right)$ and inflammatory markers in the general population (Forbes et al. 2009). Meanwhile, investigators in the United States (US) reported one year exposure to $\mathrm{PM}_{2.5}$ to be associated with high-sensitivity CRP among midlife women (Green et al. 2016; Ostro et al. 2014). In a German study, an association was identified between 365-day $\mathrm{PM}_{10}$, $\mathrm{PM}_{2.5}(\mathrm{PM}<2.5 \mu \mathrm{m})$ and number of particles, and CRP in the general population (Hennig et al. 2014). Fewer studies have evaluated the consequences of PM exposure on inflammation markers, after both short- and long-term exposure, in the same population. 
The upper thresholds for $\mathrm{PM}_{10}$ recommended by the World Health Organization are 50 $\mu \mathrm{g} / \mathrm{m}^{3}$ for a $24-$ hour mean and $20 \mu \mathrm{g} / \mathrm{m}^{3}$ for an annual mean (WHO, 2018). In Switzerland, the air quality is mostly below these values, which provides an opportunity for the health effects of relatively-low concentrations of PM to be studied in the general population.

Assessing exposure is a critical step in epidemiological studies. Many studies focusing on short-term and acute effects have relied on data extracted from air monitoring stations, taking advantage of the fact that day-to-day variations in pollutant concentrations generally are much smaller than spatial variations within a given region. For long-term studies, however, data on spatial distribution is necessary, and this requires the use of models. Our objective was to examine for associations between both short-term and longterm exposure to $\mathrm{PM}_{10}$, and several circulating inflammatory markers: C-reactive protein (CRP), interleukin 1-beta (IL-1ß), interleukin 6 (IL-6), and tumor-necrosis-factor alpha (TNF- $\alpha$ ).

\section{Materials and Methods}

\section{Study population}

The CoLaus study is a large, longitudinal, population-based cohort survey that includes residents, ages 35 to 75 years old, of Lausanne, Switzerland, a city of 117,161 inhabitants (data for 2003 from city of Lausanne population registry). The study's focus has been on cardiovascular and metabolic risk factors, as described elsewhere (Firmann et al. 2008). The Institutional Ethics Committee of the Faculty of Medicine of the University of Lausanne approved the CoLaus study. The informed written consent was obtained from all the participants. 
A non-stratified random sample of $35 \%$ of the overall population was drawn. Recruitment was done between 2003 and 2006. The sample of 8,121 subjects who agreed to participate represented $41 \%$ of the initially-sampled population ("CoLaus 1 "). Participants were asked to attend a specific outpatient clinic in the morning after an overnight fast. Between 2009 and 2012, all CoLaus participants $(n=6,183)$ were invited for a first followup (“CoLaus 2"), amongst whom 4,679 (75.7\%) accepted. Both CoLaus 1 and CoLaus 2 included standardized questionnaires (as well as questions on medications), a physical examination, and blood exams. The final sample size were 3860 subjects, who had modeling estimates of exposure levels for both waves.

\section{Health data}

During both examinations, study participants reported, for their health examination, to the outpatient clinic at University Hospital of Lausanne (CHUV), always between 7 am and noon. Fasting blood samples were analyzed for the high-sensitively inflammatory marker C-reactive protein (CRP), as well as for interleukin 1-beta (IL-1ß), interleukin 6 (IL-6), and tumor-necrosis-factor alpha (TNF- $\alpha$ ). The laboratory equipment, analysis methods used, the lower detection limit and the method to substitute values below the lower detection limit were identical in CoLaus 1 and CoLaus 2, as described earlier (Tsai et al., 2012). On follow-up (CoLaus 2), 1139, 197, and 21 values for IL-1 $\beta$, IL-6 and TNF- $\alpha$ were below the lower detection limit.

Extreme outliers were defined as those that were 10 -fold more than the corresponding measurement's $99^{\text {th }}$ percentile (p99) value; all such outliers were excluded from further analysis. The extreme outliers in CoLaus 1were described earlier (Tsai et al. 2012). In CoLaus2, no extreme outliers were detected for IL-1 $\beta(p 99=74.8 \mathrm{pg} / \mathrm{mL})$. For IL-6, there 
was one extreme outlier at $2281 \mathrm{pg} / \mathrm{mL}(\mathrm{p} 99=222 \mathrm{pg} / \mathrm{mL})$; and for TNF- $\alpha$, two outliers, of 3242 and $3793 \mathrm{pg} / \mathrm{mL}(\mathrm{p} 99=93.8 \mathrm{pg} / \mathrm{mL})$.

\section{Exposure data}

Assigning exposure to participants: Hourly $\mathrm{PM}_{10}$ concentrations at the home addresses of individuals living in Lausanne were simulated with the GRAMM/GRAL model (see below). We assigned to each participant home exposure data for one day, seven days (1-week), 30 days (1-month), 90 days (3-months) and 180 days (6-months) before their health assessment. The model was validated by comparing its output with measurements conducted at a central monitoring station in the city of Lausanne (see below). The daily modeled and measured concentrations were correlated with an $\mathrm{R}^{2}$ coefficient of 0.83 (Berchet et al., 2017). We calculated central monitoring site-time windows that corresponded to the modeled time windows for each of the participants, to understand gains in the population's exposure gradient, by using the model instead of central-site monitoring. As not all subjects lived within the GRAMM/GRAL model coverage area at both examinations, modeling data could only be assigned to 3860 participants who participated in both CoLaus 1 and CoLaus 2.

GRAMM/GRAL exposure model: A coupled mesoscale-microscale model system — GRAMM/GRAL with 5-meter grid-resolution - was set up to simulate $\mathrm{PM}_{10}$ concentrations in Lausanne. Briefly, computational fluid dynamic simulations were computed to simulate 1008 different typical weather situations that influence the threedimensional wind and concentration fields in and around the city. To generate long-term series from pre-computed reference simulations, the catalogue of simulations was "matched to observations" (i.e., situations were selected from the catalogue of 1008 
situations for which the simulated winds best matched observed winds at five different sites around Lausanne). Once the situations were identified, the simulated source-specific concentrations were scaled by characteristic time functions describing diurnal, day-ofweek, and seasonal variability of the emissions from different source types (traffic, industry, residential heating, etc.) and added together to obtain the total concentration field of $\mathrm{PM}_{10}$ (Berchet et al., 2017). This modeling did not require any local pollution measurements.

Study area and central monitoring: Lausanne covers an area of $70 \times 15 \mathrm{~km}^{2}$ and is built on the ridges and valleys of the northern shore of Lake Geneva. The highest point of the city is $600 \mathrm{~m}$ above lake level. One of the Swiss National air monitoring network (NABEL) stations is located in central Lausanne at César-Roux. A detailed description of the station can be found from NABEL website. We downloaded and averaged PM10 data into 24hour means (0:00-23:59). NABEL had missing data only during CoLaus 1 . There were $15 \%$ of hourly PM10 data missing, most of the gaps were one or two hours of missing data. This affected $27(0.7 \%)$ of the subjects' daily averages. In case of one or two hours of missing data, we replaced the missing hourly data by the weighted average of the two hours before and after the gap. Longer gaps were replaced by the average of the corresponding three daytime hours of the day before and after the gap. Outdoor air temperature and air pressure data was obtained from MeteoSwiss, Switzerland's Federal Office for Meteorology and Climatology, which provides quality-assured weather and climate services for the protection and benefit of Switzerland.

Analytic framework: to investigate the short-term effects of PM exposure, we were able to use data from both the central monitoring station and the models. For assessing effects 
of exposures longer than one month, however, only modeled data provided the necessary degree of variation related to the spatial variation between homes.

\section{Statistical analysis}

Stata 14.1 (StataCorp, College Station, TX) was used for all statistical analyses. Logtransformation was performed to approximate a normal distribution of skewed variables (CRP, IL-1ß, 1L-6, and TNF- $\alpha$ ). Descriptive results were expressed as number of participants, percentage for categorical variables and as mean (95\% Confidence Interval) or median (Interquartile range) for continuous variables. Bivariate analyses were performed using chi-square test for qualitative variables and Student's t-test for quantitative variables between the two waves.

In a prior study reported by Tsai et al., a positive association between $\mathrm{PM}_{10}$ exposure and pulse pressure and systolic blood pressure was evident only when the outdoor temperature was above $5^{\circ} \mathrm{C}$ (Tsai et al. 2015). Therefore, we created a covariate 'coldday ratio', corresponding to the percentage of days within a given exposure period when the outdoor daily average temperature was below $5^{\circ} \mathrm{C}$.

Linear mixed-effect regression models were used to examine the associations between the inflammatory markers and PM10. The outcome variables were CRP, IL-1ß, $1 \mathrm{~L}-6$, and TNF- $\alpha$, and the exposure variable was the PM10 level from modeling and monitoring stations. Each regression model included fixed effects for age, sex, BMI, smoking status, diabetes, hypertension, cold-day ratio, outdoor air pressure, and CoLaus time period. The participants were fitted as random effects in the mixed-effects models. 
Estimated effects for both long- and short-term exposure were presented as unit change per $1 \mu \mathrm{g} / \mathrm{m}^{3}$ increase in $\mathrm{PM}_{10}$. Short-term exposure interval means were 1-day, 1-week, and 1-month averages of $\mathrm{PM}_{10}$ level prior to the hospital visit (blood withdraw); while longterm exposure interval means were calculated for three and six months prior to the visit.

\section{Results}

Characteristics of the CoLaus 1 and CoLaus 2 participants are summarized in Table 1. Only participants with health and environmental data available for both data-collection waves were included in this analysis. Body mass index was lower at baseline than at follow-up. Smoking rate dropped at follow-up, while diabetes and hypertension prevalence rates increased. Except for IL-1ß, the inflammatory marker levels increased from baseline to follow-up. Table 1 also shows the distribution of PM10 and temperature. In general, concentrations in CoLaus 1 were higher than in CoLaus 2. The distributions of inflammatory markers were similar in the two waves (Supplementary Figure S1).

For short-term exposure, $\mathrm{PM}_{10}$ levels derived from the NABEL station, averaged over the 1-day, 1-week, and 1-month intervals, were positively (directly) associated with IL-1 $\beta$, IL6 and TNF-a (Figure 1). Similar results were obtained when using short-term exposure data extracted from the GRAMM-GRAL models. Long-term modeled PM10 exposure (3month and 6-month) exerted more profound effects on these inflammatory markers. For long-term analyses (3-month and 6-month), only modeled data were used, due to the small variations in long-term pollutant levels at the single, central site. No association was found for CRP with either short or long-term exposure. The $\mathrm{PM}_{10}$ levels also were associated with IL-1 $\beta, I L-6$, and TNF- $\alpha$ after dichotomizing these cytokines into high 
(higher quartile) versus low (quartiles 1 to 3 ) levels, which suggests that the associations between $\mathrm{PM}_{10}$ with the continuous cytokine were very robust to any distributional assumption, and to potential outlier values (Supplementary Table S1).

Associations between 6-month $\mathrm{PM}_{10}$ exposure levels and inflammatory markers are provided for different subject subgroups in Table 2. Six-month exposure to $\mathrm{PM}_{10}$ was significantly associated with IL-1 $\beta$ and IL-6 in men, in younger participants, and in normotensive participants; but with IL-1 $\beta$ and TNF- $\alpha$ in women and older participants. Associations with IL-1 $\beta$, IL- 6 and TNF- $\alpha$ were more significant in non-smokers. However, the interactions between $\mathrm{PM}_{10}$ exposure and the selected subgroups were not statistically significant for the various inflammatory cytokines.

In general, $\mathrm{PM}_{10}$ concentrations decreased significantly from 2003 to 2012, covering both examinations (Supplementary Figure S2). The variability in $\mathrm{PM}_{10}$ levels was greater for modeled than for NABEL data (Supplementary Figures S3 and S4).

\section{Discussion}

In the current study, short-term and long-term exposures to $\mathrm{PM}_{10}$ were associated with elevated levels of IL-1 $\beta$, IL- 6 and TNF- $\alpha$, but not of CRP. The short-term effects obtained with modeled air pollution exposures were consistent with our previous findings that used only NABEL data (Tsai et al. 2012). The long-term effects found in the current analysis also were much stronger than the short-term effects.

To date, only a few studies have assessed the association between long-term exposure to PM and CRP, IL-1 $\beta$, IL-6 and TNF- $\alpha$ in general population. In a Swedish study, IL-6, TNF-a, and CRP were not significantly associated with one-year, five-year or 30-year 
exposure to $\mathrm{PM}_{10}$ (Panasevich et al. 2009). In the US MESA study, long-term exposure (one-year) to $\mathrm{PM}_{2.5}$ was associated positively with IL-6, but not with CRP (Hajat et al. 2015). Meanwhile, in the US SWAN study, one-year exposure to $\mathrm{PM}_{2.5}$ was associated with increased CRP in women, but IL-1 $\beta, I L-6$ and TNF- $\alpha$ were not included in the investigators' analysis (Green et al. 2016).

The possible pathophysiological mechanism underlying the link between PM and systemic inflammation could be the increased production of the pro-inflammatory cytokines such as TNF- $\alpha$ and IL-6 by alveolar macrophages in response to PM (Panasevich et al. 2009 ; van Eeden et al. 2001). Prolonged exposure to PM will result in more oxidative stress and prolonged activation of cell- and cytokine-mediated pathways including apoptosis, which can progress into a chronic inflammatory response with insufficient clearance of apoptotic cells (Grabiec and Hussell 2016; Robb et al. 2016).

Interleukin 6 is an acute phase reactant released by T-cells and macrophages. In vitro studies have revealed increased production of the proinflammatory cytokines, TNF- $\alpha$ and IL-6, by alveolar macrophages in response to PM (Becker et al. 2005; Imrich et al. 2007; van Eeden et al. 2001). The stronger effects that we observed with prolonged exposure levels suggest that there is no adaptation to such exposure over time; instead, there appears to be propagation of the inflammatory process by air pollutants. This may explain the increased rates of chronic inflammatory diseases associated with living in polluted areas (Chen and Schwartz 2008). In a cross-sectional study conducted in a representative sample of elderly Taiwan residents, long-term $\mathrm{PM}_{10}, \mathrm{PM}_{2.5}$ and $\mathrm{NO}_{2}$ concentrations were all linked to IL-6 levels (Chuang et al. 2011). 
We identified no association between exposure to $\mathrm{PM}_{10}$ and circulating CRP levels, with either long-term or short-term exposure, which is consistent with most prior populationbased studies. In the US MESA study, circulating CRP levels were weakly, positively associated with exposure to 30-day and 60-day mean $\mathrm{PM}_{2.5}$ exposures, but not to shorter term (one-day, two-day) exposures (Diez Roux et al. 2006). No association between shortterm exposure to $\mathrm{PM}_{10}$ and CRP was found in the Tel-Aviv Sourasky Medical Center Inflammation Survey (Steinvil et al. 2008). Similarly, no association between long-term exposure to $\mathrm{PM}_{10}$ and circulating CRP levels was detected in 17'000 adults who participated in the Health Survey for England (Forbes et al. 2009). The absence of an association between $\mathrm{PM}_{10}$ and $\mathrm{CRP}$ does not imply the absence of an inflammatory response to PM. Rather, CRP, as a ubiquitous inflammatory marker, just might not be ideal to detect the low-grade, chronic, respiratory inflammation that can result from relatively-low levels of air pollution. One of the results identified in the European Study of Cohorts for Air Pollution Effects (ESCAPE) was that elevated $\mathrm{PM}_{10}$ levels were not associated with elevated CRP; however, living close to busy traffic was (Lanki et al. 2015).

Assessment of subgroups showed no significant interaction terms and the effect estimates were also in a similar range for most explored strata. Estimates across the various strata lied mostly well within the confidence intervals. A significant positive association of PM10 exposure with TNF- $\alpha$ levels was observed in women, but not in men, whereas similar significant positive associations with IL-1 $\beta$ and IL-6 were observed in both men and women. Participants younger than 55 years tended to have a weaker association with IL$1 \beta$ and a stronger one with IL- 6 than older participants. A significant positive association of PM10 exposure with TNF- $\alpha$ levels was observed in non-smokers, but not in smokers, 
possibly the result of the pro-inflammatory action of smoking (McEvoy et al. 2015). Normotensive participants showed a stronger positive association of CRP with exposure to PM10 than hypertensive participants, which could reflect the anti-inflammatory property of statins used by many hypertensive people (Miyata et al. 2013).

One important strength of the current study is that it is representative of the general adult population of a city. Many previously-published studies focused on specific population groups, like women (Green et al. 2016; Ostro et al. 2014), the elderly (Rioux et al. 2010) or patients. Our study also included several inflammatory cytokines, while previous general population studies only included CRP (Diez Roux et al. 2006; Hertel et al. 2010; Hoffmann et al. 2009; Rioux et al. 2010; Steinvil et al. 2008). Our longitudinal design included repeated measurements at baseline and 5-year follow-up, which reinforces the robustness of the results. A final important strength of the current study are the accurate estimates of $\mathrm{PM}_{10}$ exposure (Berchet et al. 2017), since we estimated exposures for 5meter grid-lengths at hourly intervals, using air dispersion models, also taking into account both meteorological data and emission inventories.

Some limitations exist. First, for particles, only modeled and measured data on $\mathrm{PM}_{10}$ was available in Lausanne, thus this study does not provide granularity on how much of the inflammatory response may be attributable to the size fractions $\mathrm{PM}_{2.5}$ and ultrafine particles. Second, gaseous pollutants such as nitrogen dioxide and ozone are also known to influence inflammatory processes. Third, Lausanne is a comparably clean city, thus caution should be applied when translating these findings to other, more polluted regions of the world. Fourth, exposure estimates were based on home addresses. However, we did not have the information on when the participants moved to their current addresses. 
While they are usually fairly well correlated with personal exposure (Culyba et al. 2018; Shafran-Nathan et al. 2017), they are associated with an error, which increases the uncertainty of the effect estimates. Finally, our analysis focused on PM10, but further work should extend the analysis to other air pollutants, such as $\mathrm{NO}_{2}$ or $\mathrm{O}_{3}$.

\section{Conclusions}

Our results indicate that long-term exposure to high $\mathrm{PM}_{10}$ levels is associated with elevated markers of systemic inflammation in the general adult population, when PM levels generally are low. Prolonged elevated exposure to $\mathrm{PM}_{10}$ seems to exacerbate systemic inflammatory response, which may contribute to the elevated disease risk generally observed with chronic $\mathrm{PM}_{10}$ exposure. A clear increase in effect estimates started after one month of high exposure, which suggests that reducing elevated exposures to less than one month may be helpful to reduce negative long-term effects.

\section{Acknowledgments}

We express our gratitude to participants in the CoLaus studies, and to the healthcare professionals and collaborators who have contributed to data collection. We thank MeteoSwiss for providing meteorological data, and the National Air Pollution Monitoring Network (NABEL) for providing air-pollution data in Lausanne. We thank the Direction Générale du Canton de Vaud for providing in-situ data and a pollution inventory for the city of Lausanne. The CoLaus study was and is supported by research grants from 
GlaxoSmithKline, the Faculty of Biology and Medicine of Lausanne, and the Swiss National Science Foundation (grants 33CSCO-122661, 33CS30-139468 and 33CS30148401). We also thank the funding from Nano-Tera.ch to support Dai-Hua Tsai for doing this work (grant RTD2013: 20NA20_150956). 


\section{References}

Becker S, Mundandhara S, Devlin R, Madden M. 2005. Regulation of cytokine production in human alveolar macrophages and airway epithelial cells in response to ambient air pollution particles: Further mechanistic studies. Toxicology and Applied Pharmacology $207: 269-275$.

Berchet A, Zink K, Muller C, Oettl D, Brunner J, Emmenegger L, et al. 2017. A costeffective method for simulating city-wide air flow and pollutant dispersion at building resolving scale. Atmospheric Environment 158: 181-196.

Bermudez EA, Rifai N, Buring J, Manson JE, Ridker PM. 2002. Interrelationships among circulating interleukin-6, c-reactive protein, and traditional cardiovascular risk factors in women. Arteriosclerosis, Thrombosis, and Vascular Biology 22:1668-1673.

Brook RD, Rajagopalan S, Pope CA, Brook JR, Bhatnagar A, Diez-Roux AV, et al. 2010. Particulate matter air pollution and cardiovascular disease: An update to the scientific statement from the american heart association. Circulation 121:2331-2378.

Chen JC, Schwartz J. 2008. Metabolic syndrome and inflammatory responses to longterm particulate air pollutants. Environmental Health Perspectives 116:612-617.

Chuang KJ, Yan YH, Chiu SY, Cheng TJ. 2011. Long- term air pollution exposure and risk factors for cardiovascular diseases among the elderly in Taiwan. Occupational and Environmental Medicine 68:64-68.

Colbert LH, Visser M, Simonsick EM, Tracy RP, Newman AB, Kritchevsky SB, et al. 2004. Physical activity, exercise, and inflammatory markers in older adults: findings from the 
Health, Aging and Body Composition Study. Journal of the American Geriatrics Society 52: $1098-1104$.

Culyba AJ, Guo W, Branas CC, Miller E, Wiebe DJ. 2018. Comparing residence-based to actual path-based methods for defining adolescents' environmental exposures using granular spatial data. Health Place 49:39-49.

Diez Roux A, Auchincloss A, Astor B, Barr R, Cushman M, Dvonch T, et al. 2006. Recent exposure to particulate matter and c-reactive protein concentration in the multi-ethnic study of atherosclerosis. American Journal of Epidemiology 164:437-448.

Firmann M, Mayor V, Vidal PM, Bochud M, Pecoud A, Hayoz D, et al. 2008. The Colaus study: A population-based study to investigate the epidemiology and genetic determinants of cardiovascular risk factors and metabolic syndrome. BMC Cardiovasc Disord 8:6.

Forbes LJL, Patel MD, Rudnicka AR, Cook DG, Bush T, Stedman JR, et al. 2009. Chronic exposure to outdoor air pollution and markers of systemic inflammation. Epidemiology 20:245-253.

Grabiec AM and Hussell T. 2016. The role of airway macrophages in apoptotic cell clearance following acute and chronic lung inflammation. Seminars in Immunopathology 38(4):409-423.

Green R, Broadwin R, Malig B, Basu R, Gold EB, Qi L, et al. 2016. Long- and short-term exposure to air pollution and inflammatory/hemostatic markers in midlife women. Epidemiology 27:211-220.

Hajat A, Allison M, Diez-Roux AV, Jenny NS, Jorgensen NW, Szpiro AA, et al. 2015. Longterm exposure to air pollution and markers of inflammation, coagulation, and endothelial 
activation: A repeat-measures analysis in the multi-ethnic study of atherosclerosis (MESA). Epidemiology 26:310-320.

Hassanvand MS, Naddafi K, Kashani H, Faridi S, Kunzli N, Nabizadeh R, et al. 2017. Short-term effects of particle size fractions on circulating biomarkers of inflammation in a panel of elderly subjects and healthy young adults. Environmental Pollution 223:695-704.

Hennig F, Fuks K, Moebus S, Weinmayr G, Memmesheimer M, Jakobs H, et al. 2014. Association between source-specific particulate matter air pollution and hs-crp: Local traffic and industrial emissions. Environmental Health Perspectives 122:703-710.

Hertel S, Viehmann A, Moebus S, Mann K, Brocker-Preuss M, Mohlenkamp S, et al. 2010. Influence of short-term exposure to ultrafine and fine particles on systemic inflammation. European Journal of Epidemiology 25:581 - 592.

Hoffmann B, Moebus S, Dragano N, Stang A, Mohlenkamp S, Schmermund A, et al. 2009. Chronic residential exposure to particulate matter air pollution and systemic inflammatory markers. Environmental Health Perspectives 117:1302-1308.

Imrich A, Ning Y, Lawrence J, Coull B, Gitin E, Knutson M, et al. 2007. Alveolar macrophage cytokine response to air pollution particles: Oxidant mechanisms. Toxicology and Applied Pharmacology 218:256-264.

Kaptoge S, Seshasai SR, Gao P, Freitag DF, Butterworth AS, Borglykke A, et al. 2014. Inflammatory cytokines and risk of coronary heart disease: new prospective study and updated meta-analysis. European Heart Journal 35(9):578-589.

Kofler S, Nickel T, Weis M. 2005. Role of cytokines in cardiovascular diseases: a focus on endothelial responses to inflammation. Clinical Science 108: 205-213. 
Lanki T, Hampel R, Tiittanen P, Andrich S, Beelen R, Brunekreef B, et al. 2015. Air pollution from road traffic and systemic inflammation in adults: a cross-sectional analysis in the European ESCAPE project. Environmental Health Perspectives 123(8):785-791.

Lelieveld J, Evans JS, Fnais M, Giannadaki D, Pozzer A. 2015. The contribution of outdoor air pollution sources to premature mortality on a global scale. Nature 525:367-371.

McEvoy JW, Nasir K, DeFilippis AP, Lima JAC, Bluemke DA, Hundley WG, et al. 2015. Relationship of Cigarette Smoking With In ammation and Subclinical Vascular Disease The Multi-Ethnic Study of Atherosclerosis. Arteriosclerosis, Thrombosis, and Vascular Biology 35:1002-1010.

Miyata R, Bai N, Vincent R, Sin DD, Van Eeden SF. 2013. Statins reduce ambient particulate matter-induced lung inflammation by promoting the clearance of particulate matter $<10 \mu \mathrm{m}$ from lung tissues. Chest $143(2): 452-460$.

NABEL, the National Air Pollution Monitoring Network, Switzerland. Website: https://www.bafu.admin.ch/bafu/en/home/topics/air/state/data/data-query-nabel.html

Ostro B, Malig B, Broadwin R, Basu R, Gold EB, Bromberger JT, et al. 2014. Chronic pm2.5 exposure and inflammation: Determining sensitive subgroups in mid-life women. Environmental Research 132:168-175.

Panasevich S, Leander K, Rosenlund M, Ljungman P, Bellander T, de Faire U, et al. 2009. Associations of long- and short-term air pollution exposure with markers of inflammation and coagulation in a population sample. Occupational and Environmental Medicine 66:747-753. 
Pope CA, and Dockery DW. 2006. Health Effects of Fine Particulate Air Pollution: Lines that Connect. Journal of the Air \& Waste Management Association 56:709-742.

Rioux CL, Tucker KL, Mwamburi M, Gute DM, Cohen SA, Brugge D. 2010. Residential traffic exposure, pulse pressure, and c-reactive protein: Consistency and contrast among exposure characterization methods. Environmental Health Perspectives 118:803-811.

Robb CT, Regan KH, Dorward DA, Rossi AG. 2016. Key mechanisms governing resolution of lung inflammation. Seminars in Immunopathology 38: 425-448.

Shafran-Nathan R, Yuval, Levy I, Broday DM. 2017. Exposure estimation errors to nitrogen oxides on a population scale due to daytime activity away from home. Science and Total Environment 580:1401-1409.

Steinvil A, Kordova-Biezuner L, Shapira I, Berliner S, Rogowski O. 2008. Short-term exposure to air pollution and inflammation-sensitive biomarkers. Environmental Research 106:51-61.

Tsai D-H, Guessous I, Riediker M, Paccaud F, Gaspoz J-M, Theler J-M, et al. 2015. Shortterm effects of particulate matter on pulse pressure in two general population studies. Journal of Hypertension 33:1144-1152.

Tsai D-H, Amyai N, Marques-Vidal P, Wang JL, Riediker M, Mooser V, et al. 2012. Effects of particulate matter on inflammatory markers in the general adult population. Particle and Fibre Toxicology 9:24.

Uh H-W, Hartgers F, Yazdanbakhsh M, Houwing-Duistermaat J. 2008. Evaluation of regression methods when immunological measurements are constrained by detection limits. BMC Immunology 9:59. 
van Eeden SF, Tan WC, Suwa T, Mukae H, Terashima T, Fujii T, et al. 2001. Cytokines involved in the systemic inflammatory response induced by exposure to particulate matter air pollutants (PM10). American Journal of Respiratory and Critical Care Medicine 164:826-830.

World Health Organization. 2018. Website: http://www.who.int/news-room/factsheets/detail/ambient-(outdoor)-air-quality-and-health 
Table 1. Characteristics of participants, that had participated in both waves and that had the addresses within the pollution map ( $\mathrm{N}=3860)$. The data indicates categorical data (\% of total), and continuous data (mean, $95 \% \mathrm{Cl}$ or median, $25 \%-75 \%$ ).

\begin{tabular}{|c|c|c|c|c|}
\hline & CoLaus 1 & CoLaus 2 & & Data type \\
\hline Age & $53.2(52.9-53.5)$ & $58.8(58.5-59.1)$ & $* * *$ & Mean $(95 \% \mathrm{Cl})$ \\
\hline Female, $\%$ & $1765,45.7 \%$ & $1765,45.7 \%$ & --- & Count, $\%$ of total \\
\hline BMI & $25.6(25.5-25.8)$ & $26.2(26.0-26.3)$ & $* * *$ & Mean $(95 \% \mathrm{Cl})$ \\
\hline Diabetes & $241,6.3 \%$ & $430,11.2 \%$ & $* * *$ & Count, $\%$ of total \\
\hline Hypertension & $1327,34.4 \%$ & $1686,43.8 \%$ & $* * *$ & Count, $\%$ of total \\
\hline CRP $(\mu \mathrm{g} / \mathrm{mL})$ & $1.3(0.6-2.7)$ & $1.4(0.7-2.8)$ & $* * *$ & Median (25\%-75\%) \\
\hline IL-1 $\beta(p g / m L)$ & $1.2(0.5-3.9)$ & $0.6(0.1-2.3)$ & $* * *$ & Median (25\%-75\%) \\
\hline IL-6 (pg/mL) & $1.4(0.7-3.4)$ & $2.5(1.0-7.8)$ & $* * *$ & Median (25\%-75\%) \\
\hline TNF- $\alpha \quad(p g / m L)$ & $2.8(1.8-4.4)$ & $4.8(2.7-8.5)$ & $* * *$ & Median (25\%-75\%) \\
\hline Current smoker & $1015,26.3 \%$ & $833,21.8 \%$ & $* * *$ & Count, $\%$ of total \\
\hline 1-day PM10 (NABEL) & $31.8(31.2-32.4)$ & $21.5(21.1-21.9)$ & $* * *$ & Mean $(95 \% \mathrm{Cl})$ \\
\hline 1-week PM10 (NABEL) & $29.8(29.3-30.2)$ & $21.1(20.8-21.4)$ & $* * *$ & Mean $(95 \% \mathrm{Cl})$ \\
\hline 1-month PM10 (NABEL) & $29.5(29.2-29.8)$ & $21.1(20.9-21.4)$ & $* * *$ & Mean $(95 \% \mathrm{Cl})$ \\
\hline 1-day PM10 & $22.3(21.8-22.7)$ & $17.6(17.2-17.9)$ & $* * *$ & Mean $(95 \% \mathrm{Cl})$ \\
\hline 1-week PM10 & $24.5(24.1-24.9)$ & $18.0(17.7-18.2)$ & $* * *$ & Mean $(95 \% \mathrm{Cl})$ \\
\hline 1-month PM10 & $24.8(24.5-25.0)$ & $18.0(17.8-18.2)$ & $* * *$ & Mean $(95 \% \mathrm{Cl})$ \\
\hline 3-month PM10 & $23.4(23.2-23.5)$ & $18.1(18.0-18.3)$ & $* * *$ & Mean $(95 \% \mathrm{Cl})$ \\
\hline 6-month PM10 & $21.8(21.7-21.9)$ & $18.3(18.2-18.4)$ & $* * *$ & Mean $(95 \% \mathrm{Cl})$ \\
\hline Pressure & $956.1(955.9-956.3)$ & $954.3(954.1-954.6)$ & $* * *$ & Mean $(95 \% \mathrm{Cl})$ \\
\hline Cold days $\left(<5^{\circ} \mathrm{C}\right)$ & $1293,33.5 \%$ & $691,17.9 \%$ & $* * *$ & Count, $\%$ of total \\
\hline
\end{tabular}

\footnotetext{
*** $p$-value $<0.001$. Bivariate analyses were performed using chi-square test for qualitative variables and Student's t-test for quantitative variables between the two waves.
} 
Table 2. Association of long-term exposure to 6-month average PM10 with inflammatory markers (unit change in cytokine per $1 \mathrm{ug} / \mathrm{m}^{3}$ increase in PM10) by selected strata.

\begin{tabular}{|c|c|c|c|c|c|c|c|c|}
\hline & CRP & $\mathbf{p}$ & IL-1 $\beta$ & $\mathbf{p}$ & IL-6 & $\mathbf{p}$ & TNF- $\alpha$ & $\mathbf{p}$ \\
\hline Men & $\begin{array}{c}0.0132 \\
(-0.002,0.028)\end{array}$ & 0.083 & $\begin{array}{c}0.103 \\
(0.075,0.131)\end{array}$ & $<0.001$ & $\begin{array}{c}0.056 \\
(0.030,0.083)\end{array}$ & $<0.001$ & $\begin{array}{c}0.0067 \\
(-0.009,0.023)\end{array}$ & 0.410 \\
\hline Women & $\begin{array}{c}-0.017 \\
(-0.018,0.015)\end{array}$ & 0.839 & $\begin{array}{c}0.104 \\
(0.074,0.134)\end{array}$ & $<0.001$ & $\begin{array}{c}0.040 \\
(0.011,0.067)\end{array}$ & 0.006 & $\begin{array}{c}0.019 \\
(0.001,0.036)\end{array}$ & 0.036 \\
\hline Pint a & \multicolumn{3}{|c|}{ Pint $=0.066$} & Pint $=0.405$ & \multicolumn{3}{|c|}{ Pint $=0.595$} & Pint $=0.429$ \\
\hline Age $<55$ & $\begin{array}{c}0.0052 \\
(-0.011,0.021)\end{array}$ & 0.518 & $\begin{array}{c}0.091 \\
(0.062,0.120)\end{array}$ & $<0.001$ & $\begin{array}{c}0.062 \\
(0.035,0.089)\end{array}$ & $<0.001$ & $\begin{array}{c}0.013 \\
(-0.004,0.029)\end{array}$ & 0.125 \\
\hline Age $>=55$ & $\begin{array}{c}0.012 \\
(-0.003,0.028)\end{array}$ & 0.125 & $\begin{array}{c}0.119 \\
(0.090,0.149)\end{array}$ & $<0.001$ & $\begin{array}{c}0.033 \\
(0.006,0.060)\end{array}$ & 0.019 & $\begin{array}{c}0.011 \\
(-0.006,0.028)\end{array}$ & 0.206 \\
\hline Pint a & \multicolumn{3}{|c|}{ Pint $=0.544$} & Pint $=0.215$ & \multicolumn{3}{|c|}{ Pint $=0.189$} & Pint $=0.575$ \\
\hline Nonsmoker & $\begin{array}{c}0.003 \\
(-0.009,0.016)\end{array}$ & 0.594 & $\begin{array}{c}0.102 \\
(0.078,0.125)\end{array}$ & $<0.001$ & $\begin{array}{c}0.047 \\
(0.025,0.070)\end{array}$ & $<0.001$ & $\begin{array}{c}0.015 \\
(0.001,0.029)\end{array}$ & 0.031 \\
\hline Current smoker & $\begin{array}{c}0.017 \\
(-0.005,0.040)\end{array}$ & 0.131 & $\begin{array}{c}0.104 \\
(0.062,0.145)\end{array}$ & $<0.001$ & $\begin{array}{c}0.050 \\
(0.012,0.088)\end{array}$ & 0.011 & $\begin{array}{c}0.006 \\
(-0.017,0.030)\end{array}$ & 0.596 \\
\hline Pint a & \multicolumn{3}{|c|}{ Pint $=0.743$} & Pint $=0.472$ & \multicolumn{3}{|c|}{ Pint $=0.465$} & Pint $=0.348$ \\
\hline Normotensive & $\begin{array}{c}0.016 \\
(0.002,0.031)\end{array}$ & 0.025 & $\begin{array}{c}0.095 \\
(0.068,0.121)\end{array}$ & $<0.001$ & $\begin{array}{c}0.060 \\
(0.035,0.084)\end{array}$ & $<0.001$ & $\begin{array}{c}0.010 \\
(-0.005,0.025)\end{array}$ & 0.177 \\
\hline Hypertensive & $\begin{array}{c}-0.005 \\
(-0.023,0.013)\end{array}$ & 0.567 & $\begin{array}{c}0.117 \\
(0.084,0.150)\end{array}$ & $<0.001$ & $\begin{array}{c}0.034 \\
(0.003,0.065)\end{array}$ & 0.031 & $\begin{array}{c}0.014 \\
(-0.006,0.033)\end{array}$ & 0.166 \\
\hline Pint ${ }^{a}$ & & $\mathrm{t}=0.342$ & & Pint $=0.242$ & & $\mathrm{t}=0.169$ & & Pint $=0.102$ \\
\hline
\end{tabular}




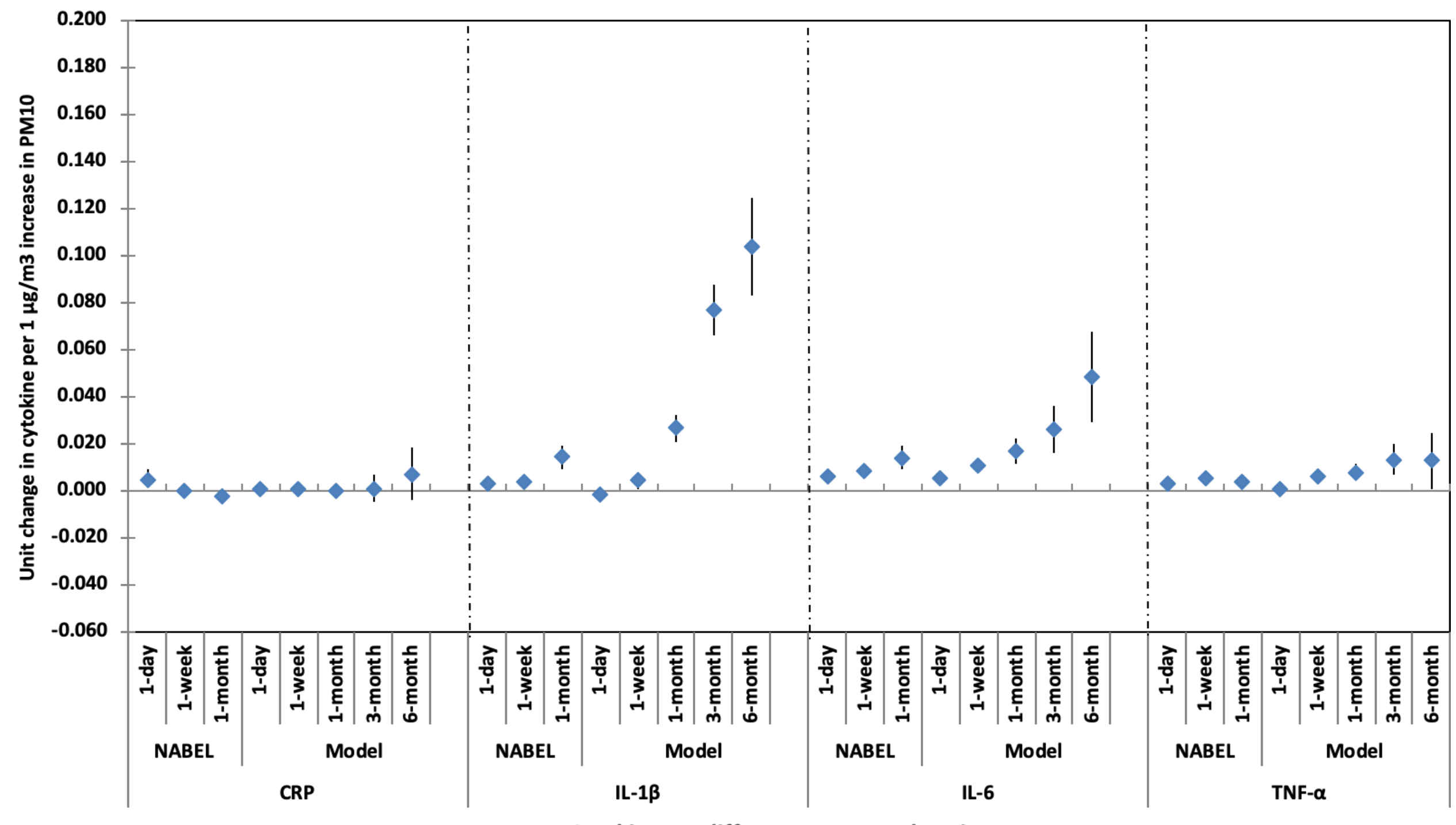

Cytokines at different exposure duration

Figure1. Association between exposure to PM10 on short-term and long-term averages from NABEL monitoring stations and Model data. Data are regression coefficients and $95 \%$ confidence intervals of mixed models. Cytokine units are $\mu \mathrm{g} / \mathrm{mL}$ for CRP, pg/mL for the other cytokines. All estimates are adjusted for age, sex, BMI, smoking status, diabetes, hypertension, cold-day ratio, outdoor air pressure, and CoLaus time period. 


\section{Supplementary material}

Article title: Effects of short- and long-term exposure to particulate matter on inflammatory marker levels in the general population

Journal name: Environmental Science and Pollution Research

Authors: Dai-Hua Tsai, Michael Riediker, Antoine Berchet, Fred Paccaud², Gerard Waeber, Peter Vollenweider, Murielle Bochud

Corresponding author: Murielle Bochud. Institute of Social and Preventive Medicine (IUMSP), Biopôle 2, Route de la Corniche 10, CH1010 Lausanne, Switzerland. Telephone: +4121314 0899; Fax: +41 21314 7373; E-mail address: murielle.bochud@chuv.ch 

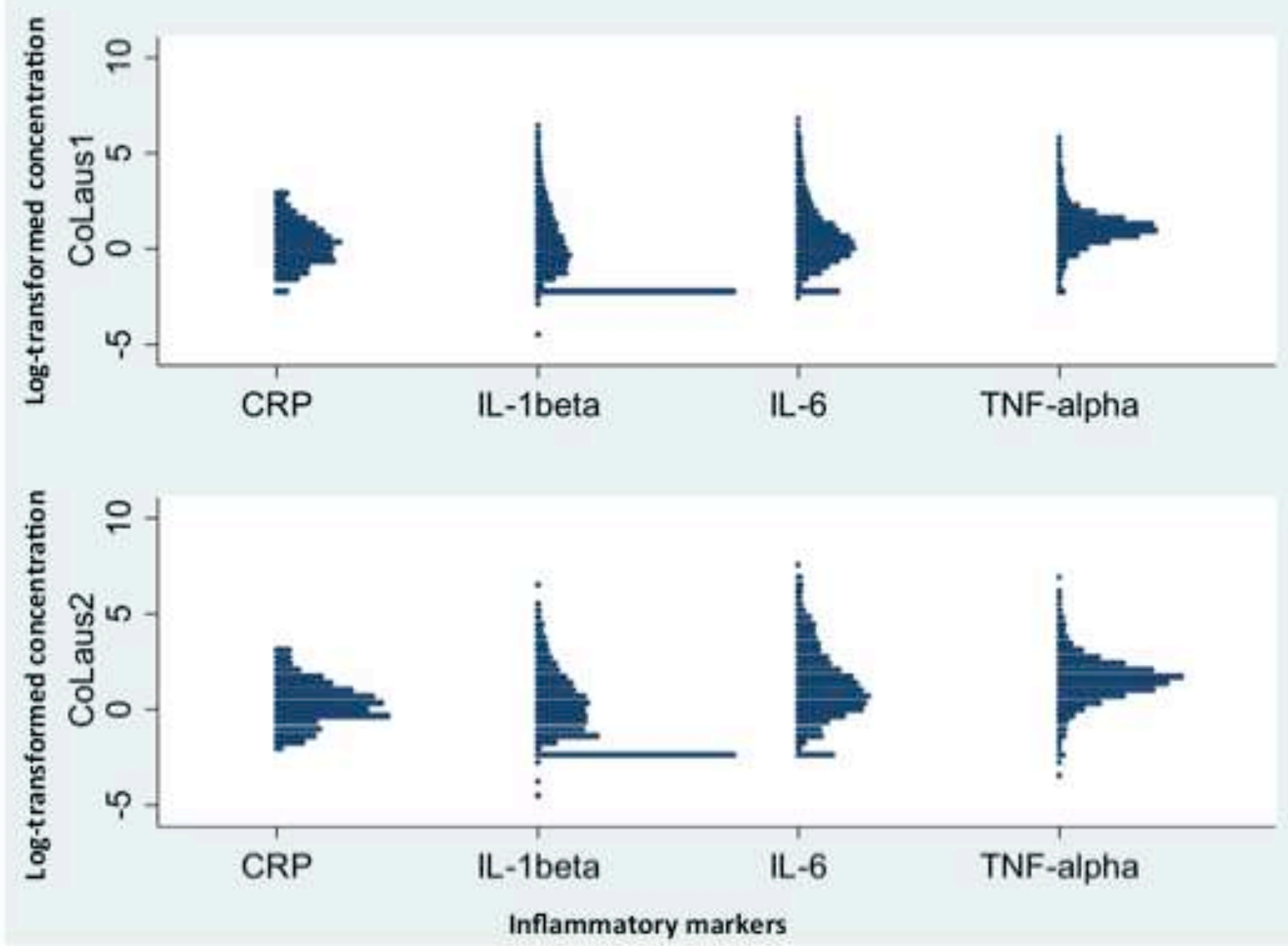

Figure S1. Dot plot of inflammatory markers in CoLaus 1 and CoLaus 2. 


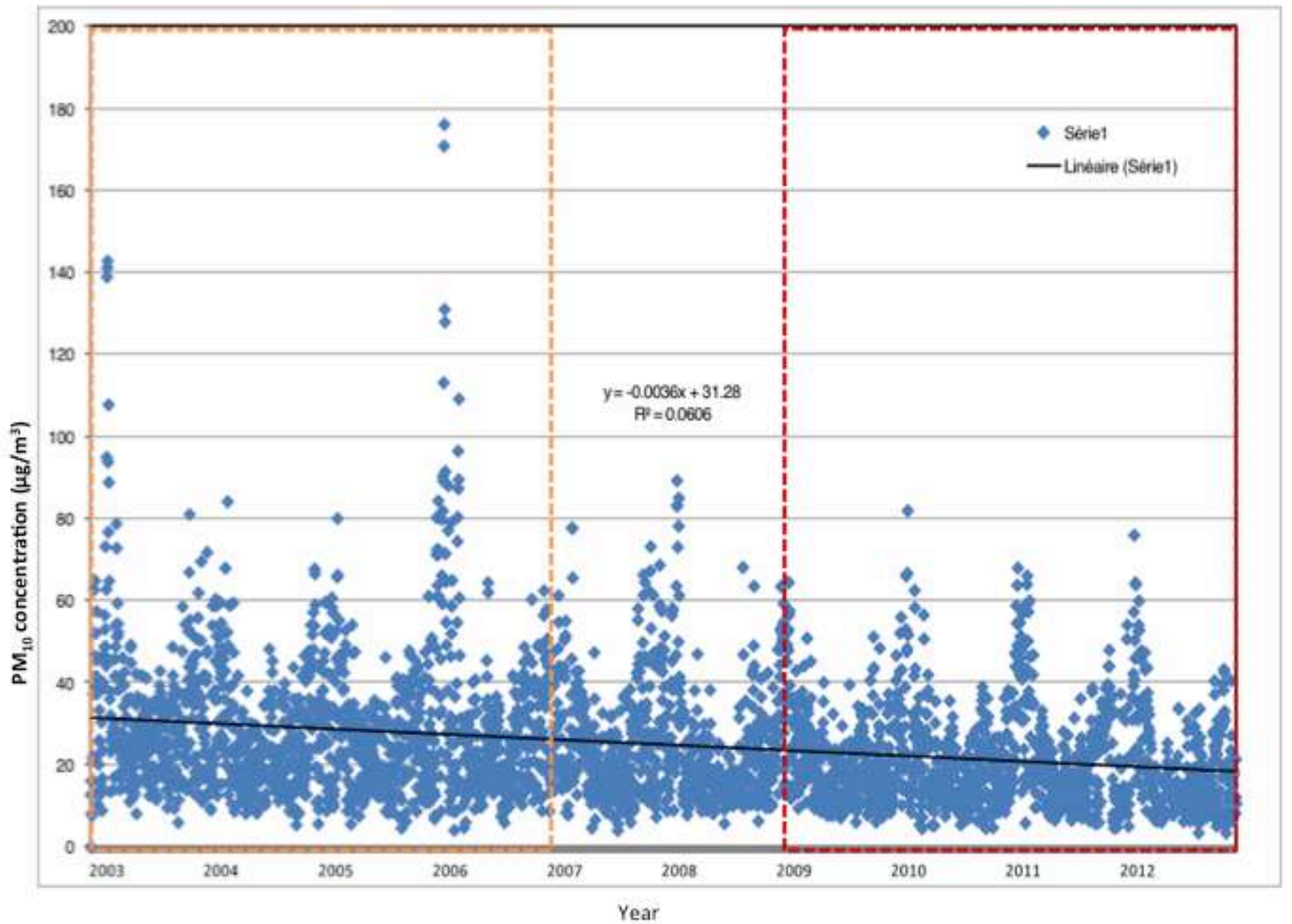

Figure S2. Daily concentrations of PM10 at César-Roux Station from 2003 to 2012 (CoLaus1 : 2003-2006, CoLaus2 : 20092012). 




Figure S3. Box plot of different averaging PM10 concentrations of César Roux station and modeled data for CoLaus1. 


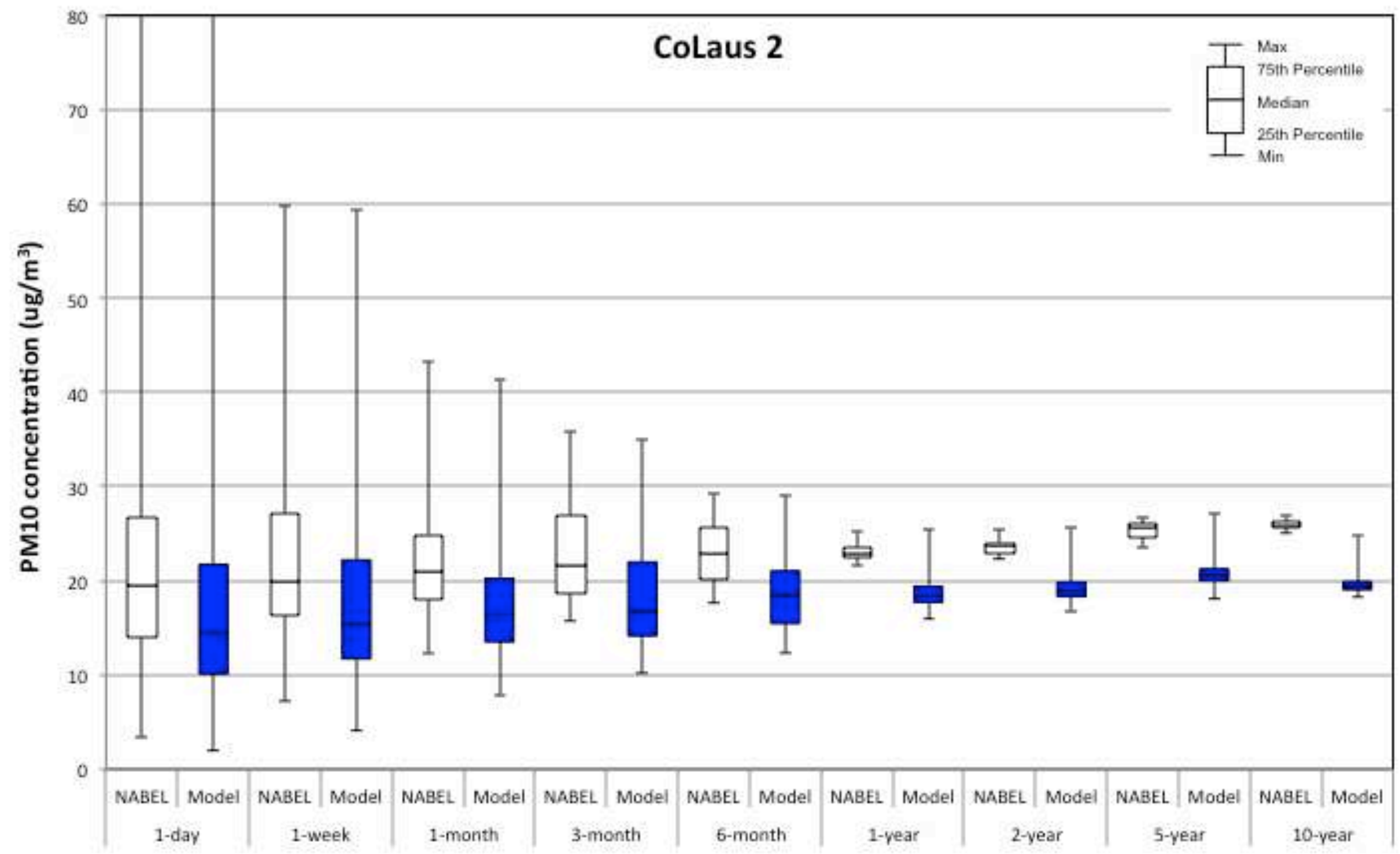

Figure S4. Box plot of different averaging PM10 concentrations of César Roux station and modeled data. 
Table S1. Association of particular matters with elevated inflammatory markers as binary outcomes $\quad$ ( $\geq \mathrm{P} 75$ vs. $<\mathrm{P} 75)$ (using 0.1 to replace ' $<0.2$ '), Odds Ratios for every $1 \mu \mathrm{g} / \mathrm{m}^{3}$ changes in $\mathrm{PM}_{10}$.

\begin{tabular}{|c|c|c|c|c|c|c|c|c|c|}
\hline & & \multicolumn{2}{|c|}{ CRP level $\geq$ P75 ${ }^{b}$} & \multicolumn{2}{|c|}{ IL-1 $\beta$ level $\geq P 75^{b}$} & \multicolumn{2}{|c|}{ IL-6 level $\geq P 75^{b}$} & \multicolumn{2}{|c|}{ TNF- $\alpha$ level $\geq P 75^{b}$} \\
\hline & & $\begin{array}{l}\text { Adjusted OR } \\
(95 \% \mathrm{Cl})\end{array}$ & $\begin{array}{c}\mathrm{p}- \\
\text { value }\end{array}$ & $\begin{array}{c}\text { Adjusted OR } \\
(95 \% \mathrm{Cl})\end{array}$ & p-value & $\begin{array}{c}\text { Adjusted OR } \\
(95 \% \mathrm{Cl})\end{array}$ & p-value & $\begin{array}{c}\text { Adjusted OR } \\
(95 \% \mathrm{Cl})\end{array}$ & $p$-value \\
\hline \multirow[t]{3}{*}{ NABEL } & $\begin{array}{l}\text { PM10: daily } \\
\text { average }\end{array}$ & $\begin{array}{c}1.002 \\
(0.997,1.006)\end{array}$ & 0.426 & $\begin{array}{c}1.005 \\
(1.001,1.009)\end{array}$ & 0.010 & $\begin{array}{c}1.004 \\
(0.999,1.007)\end{array}$ & 0.063 & $\begin{array}{c}1.004 \\
(1.001,1.008)\end{array}$ & 0.023 \\
\hline & $\begin{array}{l}\text { PM10: weekly } \\
\text { average }\end{array}$ & $\begin{array}{c}1.004 \\
(0.998,1.009)\end{array}$ & 0.178 & $\begin{array}{c}1.007 \\
(1.002,1.011)\end{array}$ & 0.009 & $\begin{array}{c}1.008 \\
(1.003,1.013)\end{array}$ & 0.001 & $\begin{array}{c}1.010 \\
(1.005,1.015)\end{array}$ & $<0.001$ \\
\hline & $\begin{array}{l}\text { PM10: monthly } \\
\text { average }\end{array}$ & $\begin{array}{c}0.999 \\
(0.990,1.008)\end{array}$ & 0.867 & $\begin{array}{c}1.011 \\
(1.002,1.019)\end{array}$ & 0.011 & $\begin{array}{c}1.015 \\
(1.007,1.023)\end{array}$ & $<0.001$ & $\begin{array}{c}0.998 \\
(0.989,1.006)\end{array}$ & 0.574 \\
\hline \multirow[t]{5}{*}{ Model } & $\begin{array}{l}\text { PM10: daily } \\
\text { average }\end{array}$ & $\begin{array}{c}1.002 \\
(0.997,1.008)\end{array}$ & 0.365 & $\begin{array}{c}0.997 \\
(0.992,1.003)\end{array}$ & 0.319 & $\begin{array}{c}1.005 \\
(1.000,1.010)\end{array}$ & 0.043 & $\begin{array}{c}0.997 \\
(0.992,1.002)\end{array}$ & 0.273 \\
\hline & $\begin{array}{l}\text { PM10: weekly } \\
\text { average }\end{array}$ & $\begin{array}{c}1.005 \\
(0.998,1.012)\end{array}$ & 0.165 & $\begin{array}{c}1.009 \\
(1.002,1.015)\end{array}$ & 0.007 & $\begin{array}{c}1.008 \\
(1.002,1.015)\end{array}$ & 0.010 & $\begin{array}{c}1.011 \\
(1.005,1.018)\end{array}$ & $<0.001$ \\
\hline & $\begin{array}{l}\text { PM10: monthly } \\
\text { average }\end{array}$ & $\begin{array}{c}1.005 \\
(0.994,1.015)\end{array}$ & 0.357 & $\begin{array}{c}1.032 \\
(1.022,1.042)\end{array}$ & $<0.001$ & $\begin{array}{c}1.020 \\
(1.010,1.030)\end{array}$ & $<0.001$ & $\begin{array}{c}1.010 \\
(0.999,1.020)\end{array}$ & 0.054 \\
\hline & $\begin{array}{l}\text { PM10: 3-month } \\
\text { average }\end{array}$ & $\begin{array}{c}1.003 \\
(0.985,1.023)\end{array}$ & 0.728 & $\begin{array}{c}1.076 \\
(1.057,1.094)\end{array}$ & $<0.001$ & $\begin{array}{c}1.046 \\
(1.028,1.064)\end{array}$ & $<0.001$ & $\begin{array}{c}1.049 \\
(1.032,1.068)\end{array}$ & $<0.001$ \\
\hline & $\begin{array}{l}\text { PM10: 6-month } \\
\text { average }\end{array}$ & $\begin{array}{c}1.003 \\
(0.971,1.035)\end{array}$ & 0.871 & $\begin{array}{c}1.091 \\
(1.060,1.123)\end{array}$ & $<0.001$ & $\begin{array}{c}1.064 \\
(1.033,1.095)\end{array}$ & $<0.001$ & $\begin{array}{c}1.066 \\
(1.036,1.096)\end{array}$ & $<0.001$ \\
\hline
\end{tabular}

a Adjusted factors: gender, age, BMI, smoking status, diabetes, hypertension, outdoor air temperature, outdoor air pressure and season. ${ }^{b}$ Cytokine levels equal to or above the $75^{\text {th }}$ percentile were coded as 1 , and as 0 otherwise. 